\title{
Consuming the Objectified Self: The Quest for Authentic Self
}

\author{
Yoo Jin Kwon ${ }^{1} \&$ Kyoung-Nan Kwon ${ }^{2}$ \\ ${ }^{1}$ Department of Home Economics, Korea National Open University, Seoul, Republic of Korea \\ ${ }^{2}$ College of Business Administration, Ajou University, Suwon, Republic of Korea \\ Correspondence: Kyoung-Nan Kwon, College of Business Administration, Ajou University, 206, World cup-ro, \\ Yeongtong-gu, Suwon-si, Gyeonggi-do 443-749, Republic of Korea. Tel: 82-31-219-3621. E-mail: \\ kwonkn@ajou.ac.kr
}

Received: November 7, 2014 Accepted: December 17, 2014 Online Published: December 20, 2014

doi:10.5539/ass.v11n2p301 URL: http://dx.doi.org/10.5539/ass.v11n2p301

\begin{abstract}
This study explores the practice of "the selfie," a self-portrait photograph, to understand what the selfie means to young adults. We examine how the people who take and share their selfies discover, present, and pursue their real selves and how this process is subject to social consumption practices. In-depth interviews with 66 young adults were conducted. Findings reveal three phases of authenticating acts in selfie practice: to embody, transfer, and use the self. The valued identity benefits that consumers obtain in selfie practice are identified; these are feeling connected, feeling in control, and feeling virtuous. Throughout the performance of multiple roles as photographers, models and users of selfie pictures, the young adults to take selfies reap benefits that are relevant to their identity projects and to their quest for their authentic selves.
\end{abstract}

Keywords: selfie, self, authenticity, self-image

\section{Introduction}

\subsection{Introduce the Problem}

Selfie is a new word that describes self-portrait photography, a practice traceable to the early 1900s (Wikipedia, 2014). The popularity of selfie has spread since 2000 with the widespread availability of front-facing camera phones such as iPhone and Samsung Galaxy. Selfies originally were the photographs that people took of themselves with their camera phones. The trend extended to group-photo taking, which now called Usie, Group Selfie, Super Selfie, and Wefie (Wikipedia, 2014). President Barack Obama made a news headline for his selfie with the prime ministers of Denmark and Britain during Nelson Mandela's memorial celebration (Soltis, 2013). This President's selfie signifies that it is no longer only limited to young people.

The Merriam-Webster Dictionary defines selfie as "an image of oneself taken by oneself using a digital camera especially for posting on social networks" (Merriam-Webster, 2014). The rise of the selfie is related to the increasing popularity of the social networking sites such as Twitter, Facebook, and Instagram. The 2014 Academy Awards host Ellen DeGeneres' selfie with a number of film stars, posted on Twitter set a record for most retweets, generating more than 1,300,000 retweets in less than an hour (Gerick, 2014). This type of celebrity selfie may be considered instant entertainment, while some selfies are time-intensive personal projects. For example, visitors to http://www.youtube.com/user/mandandcrazychild can see a 41-second time-lapse video of the hundreds of selfies of a young woman taken every day for four-and-a-half years, which shows her style changes. The question we pose in this research is what these time-consuming projects mean to the people who produce them. In this paper, we use the term selfie to include photographs of individuals, couples, and groups, in addition to the photographic practice of taking, editing, and sharing the shots online and offline.

With the selfie, the photographer is more than a photographer. The "self" in the selfie assumes is simultaneously a photographer, the photographic subject, and the user of the photos. The selfie is consumed in the forms of image modification, storing, self-appreciation, sharing with close others or even online, and obtaining feedback from them. This multiplicity of roles inevitably raises the critical importance of self-identity in this photographic practice.

Selfie is self-consumption practice (Belk, 2014). The use of online social media such as Facebook, YouTube, personal blogs, and Instagram has likewise received scholarly attention as self-consumption. The social media 
creates a virtual space in which the self is explicitly consumed. Such self-consumption is the act of both promoting the self and pursuing its authenticity (Pooley, 2010). "Consumer research literature has contended that authenticity is a socially constructed interpretation of the essence of what is observed rather than properties inherent in an object" (Beverland \& Farrelly, 2010, p. 839). We contend that the selfie culture is a newly emerging practice of exploring authenticity of self. The key to understanding this consumer culture is social aspect of this seemingly self-centered practice. People take control of when, what, and how to take selfies for their own sake. However, selfie practice should also be understood as social consumption practice, which is highly managed, orchestrated, and strategized in the social context; taking, posting, and sharing selfie photos is, for the most part, accompanied by exposure to, interactions with, and feedback. Social interactions, posting selfies and obtaining comments from others, are only half of the activities. The other half that involves production of pictures is not isolated from social interaction. What people attempt to present through their photographed self-images is based on who they think they are and who they want to be; the concept is socially shaped through interactions with others. The production and use of selfies thus resembles what Belk (2014) called our online presence, which, he argues, can be more purposely managed compared to the one in the traditional face-to-face encounters (Belk, 2014). This study examines how consumers engage in discovering, presenting, and pursuing their real self and how this process is subject to social consumption practice. We believe that selfie photography in this digital age is a good context in which to research the pursuit of self-authenticity in consumption practice.

There are certainly discussions of the dark side of self-consumption, such as including narcissism, lack of integrity, and self-commoditization (Belk, 2014; Pooley, 2010). However, we have a more positive understanding of this intriguing new consumer culture. Our findings, based on in-depth interviews with 66 college students will enlighten the ways in which social selfie practice, which appears to be highly self-centered, leads to the affirmation of the authentic self.

\subsection{Study Background}

Since the conceptualization of self as "the sum total of all that he CAN call his, not only his body and his psychic powers, but his clothes and his house, his wife ....his reputation and works .... and bank account" [emphasis in the original] (James, 1890, p. 188), self is conceptualized from various angles, reflecting the nature of discipline. The psychology of self construes the self-structure. James and Mead note the dual function of self: the $I$, the self-as-knower, and the $M e$, the self-as-known (Schlenker, 1980). The $I$ is the active and subjective aspect; while the $m e$ is the empirical and socialized aspect of a person. The $I$ act and react, not judging myself. It is the experiencing being of sensing, thinking, behaving, and so on. Therefore, the I cannot be experienced, but it is "the process that characterizes the thinking person" (Schlenker, 1980, p. 48). At the same time, the me refers to the person's self-perception, the knowledge about oneself. The me is learned in interpersonal interactions. Therefore, the me evaluates itself as object. The $I$ appears experientially as a part of a me (Mead, 1934, p. 176). According to Mead's notion, the $I$ acts creatively within the context of the me. That is, a person composes a response on the basis of the $m e$, what is socially learned. Thus, the I as well as the me are not alienated from the value system of the society (Mead, 1934). The symbolic integrationist notion of the $I$ and the $m e$ is similarly found in a psychoanalytic theorizing about the self. Havens (1986) contends that the self arises out of the relation between ego and superego and the self includes ideals, fantasies, defensive styles, and prohibitions, integrating psychoanalytic theories of self (p. 370).

This dual notion of self (i.e., the subject and the object) does explain self-reflection. The self is the agent that reflects and the object that is reflected on (Havens, 1986). The reflective process relates to the authentic self. The authentic self develops from acknowledging impulse and prohibition (Havens, 1986). In other words, self-authenticity emerges in the reflective process of accepting what the self instinctively wants and values or self-consciousness.

Authenticity is discussed in relation to a variety of consumption objects. Historically authenticity, as being true and genuine in essence, is an incompatible concept in characterizing commercial objects, as selfish material motives are obstacles of achieving a state of self-authentication (Beverland, Farrelly, \& Quester, 2010). However, consumer research, particularly since the late twentieth century, notes that consumers search for authenticity in consuming commercial objects and services. Consumers' search for authenticity is understood as response to modern society where considerable portions of societal experiences are commoditized and many forms of consumption objects and services are virtualized and ambiguous in determining whether they are real or unreal (Baudrillard, 1994; Berger \& Luckmann, 2011; Pine \& Gilmore, 1999).

Authenticity has become highly sought after by individuals and groups. Authenticity is sought not only in 
commodities and experiential products (e.g., tourism products) but also in brands, media contents, and subcultural identities. Marketers also seek authenticity. As authenticity, being an evaluative criterion, determines product value, it becomes an important either to discover or create the authenticity of products or services. Strenuous marketing efforts are made to produce authenticity, even though the premise of authenticity is it is an inherent quality (Vannini \& Williams, 2009). Vannini and Williams (2009) maintain that authenticity has become "the objectification of a process of representation" (p. 3). In other words, authenticity is "a set of qualities that people in a particular time and place have come to agree represent an ideal or exemplar" (Vannini \& Williams, 2009, p. 3).

Academics have attempted to understand the components of authenticity. The research has conceptualized authenticity in consumers' perception based on the cues which consumers use to determine what is and is not authentic (Beverland \& Farrelly, 2010; Leigh, Peters, \& Shelton, 2006). Three types of authenticity are found: indexical, iconic, and existential (Grayson \& Martinec, 2004; Leigh et al., 2006). Indexical authenticity is established by a factual and spatiotemporal connection to history. Handprints on the Hollywood Walk of Fame are perceived to be authentic because of the physical link to the actors (Grayson \& Martinec, 2004). In a person's actions or expressions, authenticity is assessed by self-assurance about cultural ideas or identity that the actions or expressions embody, that is, how much the actions or expressions reflect who the person really is (Leigh et al., 2006). For example, a dance performance by members of an ethnic group is authentic when the dancers truly embrace their cultural heritage in their identity instead of simply going through a dance routine (Grayson \& Marinec, 2004). Iconic authenticity is embedded in the phrase "authentic reproduction" (Grayson \& Marinec, 2004). When something physically resembles what is indexically authentic, the object is considered iconically authentic (Leigh et al., 2006). Assessment of iconic authenticity requires a basic sense of the original for comparison.

Lastly, Wang (1999) proposes existential authenticity as an activity-based concept, while the two former types of authenticity are object-based. Existential authenticity relates to postmodern consumption in which reality to consumers is based on their perceptions of "staged authenticity" (Pooley, 2010, p. 78) owing to technology that can change an inauthentic to an authentic look (Grayson \& Marinec, 2004). When consumption generates creative and cathartic feelings that make consumers feel more expressive and truer to themselves, they perceive those experiences as real (Wang, 1999). Existential authenticity is perceived when a consumer feels that his or her true self is experientially connected to the real world (Grayson \& Marinec, 2004). Existential authenticity is established through engagement of self in the process.

Commodities are consumed through activities and experiences; the implication of existential authenticity is vital. Existential authenticity as the activity-driven state of being is first proposed in the context of tourism. It can be expanded as the experience-driven state of being in order to apply to a broader context of consumption. It is inevitable that experiential products are accompanied by engagement of self. In fact, existential authenticity is found in the context of object authenticity. Beverland and Farrelly (2010) find that consumers pursue authentic consumption objects with specific personal goals in mind. Consumers focus on particular cues in objects that would gratify their desire for identity benefits such as feeling of control, connection, and virtue. Their study accounts for the motives of consumers' quest for authenticity in consumption.

The consumer-object relationship is conceptualized by the theory of extended-self (Belk, 1988). Belk makes the ontological connection of self and possession on the basis of Sartre's (1943) three states of existence (i.e., having, doing, and being). Belk's proposition explains how an object earns existential significance through the chain link of possessing-acting-being. Belk's theory of extended self becomes theoretical foundation of later studies on self and consumption objects (Ahuvia, 2005; Gao, Wheeler, \& Shiv, 2009; Nuttall, 2009). Although his theory originally puts emphasis on the ontological meaning of possession, the role of "acting" (i.e., doing) relates to existential authenticity in a consumption context where experiential value is important. By controlling and creating, a consumption experience that provides pleasure and catharsis is integrated with one's self-concept. The experience that results in the subjective feelings of the real self becomes real to the individual even though the experience involves fantasy or artificiality.

Assessment of authenticity of self is different in that there is neither reference nor a person to authenticate. Self-authenticity emerges from reflexive process of self-affirmation (Havens, 1986; Weigert, 2009). Weigert (2009) characterizes self-authenticity as an aspect of self-motivation. Self-authenticity is "a means of self-positing," that is, "I am what I experience as who I am" (Weigert, 2009, pp. 38-39). Weigert (2009) draws this perspective upon self-reflexivity of Mead's conception of self as I-and-me and self-and-object. Dialogical self-concept is reflected in the following: "The $I$ in memory is a $m e$, but it is a $m e$ which was the $I$ at the earlier time" is the me in present" (Mead, 1934, p. 174). Weigert (2009) proposes self-authenticity as the master motive 
that informs other motives including self-values, self-efficacy, and self-esteem, adapting Gecas' (1991) conceptual framework of self as motivational force. On one hand, self-authenticity as meta-self motive makes one experience value, efficacy, and esteem as mine. On the other hand, self-authenticity motivates social actions, as self is "continually experienced and constructed" within the dynamic relations between $I$ and $m e$ of self and others (Weigert, 2009, p. 38-39). Self-motive arises from the past, provides a reason for present actions and proceeds toward a desirable future (Weigert, 2009).

\section{Method}

A qualitative method was adopted. Data were collected through in-depth interviews with 66 Korean college students. The use of the Korean sample is particularly beneficial, since Korea has one of the most vibrant selfie cultures and is also a collectivistic culture in which social interactions greatly contributes to shaping self-concept All participants indicated they frequently took selfies. The participants ranged in age from 19 through 27. The majority of participants are 19-23 years old. Detailed information about participants can be provided upon request.

Trained research assistants conducted semi-structured interviews for 30 minutes to an hour at places which participants preferred, including dormitory rooms, coffee shops, and library study rooms. Participants were asked general questions about their selfie practice (when, where, how often they take selfies, and what they do with selfie pictures), about their selfie-taking skills and techniques, selfie-related memories and experiences, the use of image-editing software, reasons for taking selfies, what makes a selfie good or bad, and how to post and use selfies. Interviews were video-recorded and transcribed verbatim.

Transcripts and observations were analyzed with coding strategies of grounded theory; preliminary codes emerged through open coding and on the basis of open coding, axial coding was implemented relating codes and concepts emerged. A table of coding categories was then developed. To ensure trustworthiness, the clarity of the codes was checked by having a third person, who has field expertise, code the data. Through this process, the categories of codes were clarified and revised. As a final step, selective coding was conducted by the two authors and the third person by rereading and coding all of the data (Glaser \& Strauss, 1967). The interviews were originally conducted in Korean. Quotes reported in this article were translated into English and back translated by two bilingual researchers to confirm the accuracy and trustworthiness of translation.

\section{Findings}

Three phases of authenticating acts emerged in selfie consumption and the valued identity benefits that consumers derive from the acts were identified.

\subsection{To Embody Self}

A selfie is taken either alone or as a group. This first phase is a process of embodying the features of one's self-image on selfies. A selfie is a means of capturing a momentary image of oneself. This process has two aspects: visualizing and recording. The selfie enables people to see themselves at different moments. They do not get to see themselves otherwise. Participants stated that they sometimes took selfies in lieu of looking at themselves in the mirror. However, the data illustrates that selfie is much more functional than a mirror. The reflection of self in selfies is twofold. The selfie is a means of discovering self and of self-expression. Many participants stated that they were able to learn about their appearance by looking at different images of themselves in selfies:

P35 (female): I can be a third person and reflect on me. It makes me think about different aspects of myself.

P8 (male): Selfie reveals facial expressions that I was not aware of. ... Selfie makes me realize "This is how I look." When friends tell me "you don't look good today," then I take a selfie [to check myself]. I think that what is in my mind appears in selfies. Not until I see my selfie that I realize what is deep in mind. That is why I take a selfie once in a while.

These participants believed that selfies helped them to discover both their external and internal selves. Appearance is particularly important in the formation of self-image in adolescents and young adults, who are the people most likely to take selfies. Many participants started taking selfies when they were in junior high or high school. They stated that they learned about different ways that they can look, and which they cannot usually see. As participants habitually took selfies, they encountered unexpected photographic images that were not originally in their body image. This experience intrigues adolescent and young adult consumers who have a strong interest in discovering and exploring their self-image.

Selfies also prompted participants to discover their mental state. P35 saw herself as if she were the third person. 
By seeing her facial expression in her selfies she could see the state of her mind. At the same time, she is able to interpret the pictures because she is the subject. She thus believed that the selfie was a genuine reflection of her internal self. Therefore, the selfie provides a new experience of self-discovery and self-interpretation.

A flattering picture, or "a good selfie," is very important. In Korea, the slang term for attractiveness on a given day is the state of the day. Most participants, both male and female, stated that they took selfies when they were at their most attractive, when they were dressed up or when their hair and make-up were well done. Consumers' mental image of their appearance (i.e., body image) changes daily. The quest for a good selfie is a person's wish to keep a record of the day when he or she has a good body image. Selfies are visual record of their high self-esteem.

In addition, selfie takers meticulously develop techniques of getting good selfies. Many discussed camera angles, lighting conditions and how to work with their face and body. More elaborate techniques include how to take a selfie that does not look like a selfie, tips for group selfies, effective use of backgrounds and tools such as tripod or self-timers, and image editing. The acquisition of such extensive knowledge and techniques for good selfie reflected how deeply the participants were involved with this practice and how proficient they were.

Selfie-takers' efforts are not simply an effort to document their good looks. The following quote about photography skills suggests the $I$ and me $M e$ state that the selfie requires:

P84 (male): Set very bright lighting, tilt down the face, and hold a camera high. Then I can get a picture of a person who looks like celebrities. ... When you have puffy eyes, take a selfie in a place where you get less light. Darkness will make it up. If you are proud of fair skin, take a selfie in a bright place. It will smooth out the facial features [and it highlights the fair skin] and you will like it. An example of my special skills is to portray well-moisturized skin. Take a shower, lightly towel dry, apply moisturizer, and take as many as selfies within 2 minutes. That's my secret method.

P84 therefore would have not taken a selfie when he had puffy eyes because he would not get good selfies at that time. He did find a way to hide the puffiness. The selfie is not only an objectified form of the self that is simply photographed, but also embodies active aspect of self who photographs. Good selfies attest to the photographer's ability to present his or her body and ideas in a given external environment.

As observed in most consumption practices, a selfie is also useful for self-expression. Participants expressed their physical attractiveness, their personality, and seasonal and other themes of their choice. All participants agreed generally on the importance of camera angle, lighting, and facial expression, but their preferences for angles or lighting differed. For example, some preferred dormitory bathrooms that were neither too bright nor too dark. Some male participants preferred moderately dark places because it created the right amount of shadow to show off their muscles. The goals and evaluations of selfies were highly personal, and participants thus valued their own judgment and skills. In other words, good selfies were not simply flattering photographs, but the way that $I$ want to portray $m e$ :

P56 (female): The important reason [to Photoshop selfies] is to make pictures in the way I look at myself. Photos do not reflect the reality.

P64 (male): I am a kind of blunt person. ... Occasionally people think that I am angry when I have no facial expression. And I am an introvert and not good at expressing [when I am with strangers]. Of course I do talk a lot and I'm outgoing when I'm with close friends. ... So I take a selfie with lots of expression and have a picture shown to a stranger first [on social networking sites] before we meet in person. Then I expect that the person will understand me better and feel comfortable meeting with me in person.

Participants suggest that discovery and expression of self are not separate. By posing for, taking, and reviewing selfies, a person learns to use his or her facial expressions and body gestures and thus the person becomes more comfortable with self-expression:

P48 (male): If I do not look in the mirror, I can never see myself. I thus cannot evaluate myself and I think of me based on what others talk about me. As I take numerous, not one or two, selfies in everyday life, I get to think, "Umm, this is how I look" or "I see. I can express myself in this way." In other words, I learn about different aspects of myself. ... I get addicted [to selfie] because the more I take selfies, the more I discover myself. It is fun. I take more because it is fun. As I take more and more, I learn more about how to express myself. ... I think the best way to learn about oneself is taking selfies.

A selfie is existential reflection of the self. Selfies put people in a position in which they can see how they appear to others. By implementing a variety of techniques and by managing environment and self, they are able to produce a medium that delivers positive images of self and that is expressive of various messages related to the 
self. Selfies are concrete representation of an abstract idea about the self.

\subsection{To Transfer Self}

The next phase is the transfer of the carefully engineered form of self from the private to the public field. Among numerous selfies, some are publically shared on social media and the rest are stored in a private place such as a hard-drive or in a cellphone memory. With the popularity of social media, photos provide new and up-to-date contents. Visual contents are particularly interesting and popular to audiences. For them, selfies which document the everyday self in addition to the self on special occasions are very attractive objects to post.

Many participants stated that one of the major reasons for taking selfies was to communicate on social media. While selfies are produced in fairly secluded environments, selfies are transferred and presented in public to represent who one truly is and what one wants to say. Social media provide the convenience of making selfies accessible to all online acquaintances by one click. Instead of corresponding with individual, consumers post their selfies and wait for the reactions. Participants want to update others on what they had recently been doing and to have conversations about it:

P72 (male): Well ... For example, when I am in a relationship, I post my selfies [taken with my girlfriend]. Actually, my homepage in Cyworld have mostly guy visitors. I do not keep in touch with them too often for every detail in my life. But when they see the selfie [with my girlfriend], they contact me. It is a way of communicating with them. They ask if she is my new girlfriend.

Participants' opinions on the uses of selfies on social media are complicated. Although they were eager to receive comments about their selfie postings, they let visitors decide whether or not to initiate interactions. They admitted that they used selfie posts to show off their appearance, their love relationships, trips to special places, or their achievements. They preferred posting selfies online because they believed that it was more appropriate than direct communication. They did not want to appear to be bragging:

P63 (female): If I get back from travel, I post selfies giving a hint of trip to XXX rather than directly saying "I am back from a trip to XXX." When people see the postings, they will get it.

Interviewer: Why do you want to give a hint?

P63: It is a bit shame to say it upfront. If I post selfies taken in Paris, you would talk to me saying, "Hey, you went to Paris." The conversation becomes more spontaneous.

Interviewer: What does the spontaneous conversation mean to you?

P63: It means that I am not showing off. I can let others know what I have been doing in a modest way.

Posting a selfie that is created from an active aspect of a person is a ritual of reaching a state where a consumer exercises self-perception as object. Through this ritual, they put their self out in a public space and prepare for the next phase, which is social engagement.

\subsection{To Use Self}

The third phase is the use of selfies. Selfies in public elicit social interactions. Friends view and comment on one's selfies on social media and the owner of the pictures responds. The consumption of selfies is unique. Without other people's reactions to the selfies, consumption of the selfies is not complete.

The performance of a selfie at this phase is gauged from the others' reactions to that selfie. Flattering or humorous selfies and interesting scenes make a person interactive with his or her online friends. No matter how interesting the selfie is, it is essential keep adding new posts:

P17 (female): The number of visitors heavily depends on the number of updates. So does the number of comments. The number of visitors or comments won't last. When there is an update, the announcement goes to friends for a few days. For these days, the number of visitors goes up and then goes down. Therefore, I upload new pictures [continually].

Selfie consumption is thus an iterative process; consumers produce new selfies and update their space on social media. Then they are engaged in social interactions through the medium of selfies posts. In order to maintain the level of interactions with their online friends, they need new contents and thus produce new selfies.

Through the iterative practice, three types of valued identity benefits emerged. According to Beverland and Farrelly (2010), the authenticity of a consuming object (i.e., products, brands, and experiences) is rendered when the consumption addresses a consumer's self-relevant goals. The goals are contingent upon the identity benefits that consumers value. The identity benefits similarly emerged from our data: feeling connected, feeling in control, and feeling virtuous. These identity benefits are gained from the practice of selfie, when the consumer 
performs multiple roles as a photographer, a model and a user of selfies.

\subsubsection{Feeling Connected}

Staying connected emerged as the foremost benefit and goal. Participants insisted that their reason for taking selfies is to feel connected. Many participants stated that they took selfies when spending time with friends; those pictures are posted in order to share with the friends who were in the pictures instead of emailing the pictures. With selfies taken alone, they solicit comments from friends.

Participants were compensated for the enduring efforts made to create interesting selfies and captions when they acquire a sense of connection from selfie practice. The amount and the contents of comments would make an impact on how they think about themselves (e.g., how sociable they are):

P27 (female): Simply ignored. Sometimes no comment is worse than malicious comments. Malicious comments are still signs of interest.

P16 (male): It hurts. In fact, last night I posted a selfie and no one commented on it at all. It hurts my feeling.

Interviewer: Did you take any actions in such situation?

P16: Yes. For example, I could rewrite the text that belongs to the picture. Or I put a funny comment on my selfie to increase responses [to draw attention].

P8 (male): It [Being remembered by others] means that I am connected to those people and they have interests in me. I really like that. I don't like to be alone. Feeling connected gives me contentment. The contentment means a lot to me. Cyworld is a tool and selfies connect the people and me.

Participants managed and maintained the closeness of their social circles through the selfie practice. The selfie is a highly personalized method of communication, although selfies are shared through a communication channel that is generally considered impersonal:

P6 (male): Well, ... I am still young, but things keep me busy from seeing friends often; it is very rare. So I get to know how they are doing from their selfies, reading what is written there, ... It is a communication tool for young generations now. ... Well, I think email is a communication tool that is emotion-less, so I don't do emails. I rather write letters. My photos in my homepage at least tells how I am doing, maybe I am getting old? It shows in my face. They will know my feelings about how my life goes. When I see my friend's picture taken at his job, I can figure how he is doing with his colleagues, how things are going. I do not have to talk long, I know he is doing good, I get connected.

Some participants even expected to make new friends and were able to expand their social circles through the selfie practice; the interactive nature of social media made this possible:

P22 (male): It was a selfie with friends at one of the outings. Someone who saw the picture sent me a message saying that I looked like a good person and having outgoing personality. Then the person asked me to be a friend with him [It was friendship, not a romantic relationship] Selfies work like this.

P71 (female): As I told you, the reason for posting is ... not for those who I don't know very well. And I am a shy person. It is not to get to know complete strangers; among the acquaintances, I want to expand my social circle. In other words, I want to show what my life is like by showing my selfies and I want to interact with the people. It is not that I want to advertise myself.

Even though not every group selfie not posted on social media, the act of taking a group selfie became almost a ritual signifying friendship, intimacy, or, at least, getting acquainted. Many participants described the behavior per se as a social activity.

Participants also obtain relationship confirmation through selfie. For example, a selfie is one way of fostering and confirming a romance:

Interviewer: Why do you post the pictures in which your girlfriend looks good?

P76 (male): Those who have girlfriends might understand; I feel better hearing "your girlfriend is pretty" than hearing "you look handsome."

One reason participants posted their selfie pictures with the new significant other is to solicit endorsement from their friends and to have their partners accepted into their social circles.

\subsubsection{Feelings in Control}

Participants pursued, had, and enjoyed the feelings in control through the process of taking pictures, posting them, and commenting on them. First, consumers control the production of the pictures: 
Interviewer: Then why wouldn't you ask someone to take a picture of you at those places?

P59 (male): Those pictures feel completely different. The picture taken by someone else feels like I was added as a supplement to the scenery. It is like the difference between active and passive voice. The feeling of stepping into the scenery by myself [in selfie] is one thing, and the feeling of fitting me into the scenery is another thing [in a picture taken by others].

They felt in control because many elements can be arranged in selfies. As explained in 3.1, they believed that selfie photographic techniques gave them control of their pictures. With the photographer and the model being the same person, photographing strategies are integrated with strategies that make a subject photogenic. Participants meticulously positioned themselves and others and manipulated the surroundings to make the kind of pictures they were envisioning. Here is an example of controlling the position in group selfie:

Interviewer: So you mean you tell your friends where to stand [when taking a group selfie]?

P18 (female): Yes, I take pictures, selfies with my friends. But I get to control things like angles or timing. [It's like] "you stand here, you there, and ... [on the count of three] one, two, three!"

Selfie takers select some of numerous almost identical pictures, to post online or to store on their cell phones. It is necessary to have an eye to select pictures that fit the intention of the post. On the Internet, participants believed that they could manage and control interactions with peers to some extent. If they want to keep a good relationship, complimenting friends' postings is one way. If they want to avoid someone, they can simply ignore his or her postings.

The process is reciprocal and continual; people comment on each other's selfies.

Interviewer: Do you often comment on friends' postings?

P10 (female): Yes, pretty often, when friends update their homepages or walls. A friend of mine posts their selfies wearing horn-rimmed glasses and with dirty hair with caption "this week is exam week." Then I express my interest in the friend by commenting, "You must be pretty busy. Let's hang out after your exams." He also shows interest in me. We exchange a lot of things through selfies.

Another way to control the relationship is to appreciate other people's pictures. As the contents of comments may affect the quality of the relationship, it is much better if a commenter tailors the comments to the receiver:

P15 (female): About what I did and felt, I hope they feel the same. Looking at my selfies, I hope that they understand and comment as I experienced and felt.

Other feelings of control come from setting personal boundaries. On some social media, there are easy ways to control the extent to which people interact with friends and relatives. They can designate which group sees which pictures:

Interviewer: About getting attention ... You must have good friends, but you may not like some of your friends [i.e., acquaintances]. Do you have friends whom you do not like to see your selfies?

P5 (female): Yes. I told you I do Cyworld. [On Cyworld] there is a certain function that allows you to select to whom you want to show your pictures and you do not want to. I can do that.

Looking glass self-theory provides a cue to understanding the importance of control in selfie practice. People never see their actual appearance or how they actually look to others. Instead, they imagine how they must appear to others and how others judge them; this leads to a sense of self (Yeung \& Martin, 2003). In the online context, pictures and texts mediate interpersonal communication. They still cannot see themselves in person, but they can select images for others to see. People would be eager to create "good pictures" to control the judgment of others. In short, by taking, posting, and commenting on pictures over time, participants believed that they are more capable of managing their interpersonal relationships.

\subsubsection{Feeling Virtuous}

Consumers find the virtue of a product when they accept the product as genuine one (Beverland \& Farrelly, 2010). Participants articulated the virtue of upholding moral principles in selfie practice. They explained that the selfie was to highlight their positive inner self, not to display misleadingly flattering pictures, although good selfies are the ones that portray the self as more attractive. Participants were self-conscious about having good selfies because it implies false self-enhancement. They want to feel that selfies do them justice; what the pictures portray is neither better nor worse than real self. P70 describes genuinely good pictures:

P70 (male): Good pictures? Well, first of all, it means the person looks handsome in the picture. And I remember my favorite look of me reflected on mirror. A good picture captures that look. Because I believe how I look in the 
mirror is same as how I look to others, I think a good picture portrays the actual me in that look.

P70's statement suggests her perception of good selfies. Selfie takers believe a good selfie should depict the self in a flattering but realistic way. Participants want the pictures to stay true. Unflattering pictures are deleted and they also have the limit of flattering pictures to call selfies genuine self-images. The parameter is developed through interactions with others. Participants set standards to determine whether selfies of others went beyond the limits. They expected overly good pictures to elicit negative feedback or derision behind their back:

P75 (female): Sometimes I look super pretty [in selfie], it doesn't look like me. Too bad, I can't post it, because it is too good.

Interviewer: Why not?

P75: It's pretty obvious. I probably hear "it's a scam." I am ashamed to post it as my picture when it doesn't look like me.

Although some used it, many participants refuse to enhance or manipulate photos using computer software such as Adobe Photoshop. Instead they worked on their photographing skills:

P17 (female): I am negative about touching selfies up on the face. ... I would rather select good pictures [to post or share]. It is too much to try to appeal to someone with the artificial images. Let's say I become to look great in the edited images, but I am not the person in that artificial look. And I think the level of satisfaction goes down.

Participants ensured the authenticity of selfies by expressing genuine feeling in the pictures. Whether appearance or internal thoughts, they found the virtue of selfie in its representation of reality:

P23 (male): My feelings should fit the pictures that I want to be. If I want a picture of a man who enjoys coffee with dignity and I am not such person, then it does not make sense to take such selfies ... I can get good selfies when I have a genuine feeling.

P64 (male): Selfies can capture what people cannot see in me.

Efforts to embody genuine feeling are related to a sense of honesty. They want selfies to honestly express the unknown side of self to friends. Participants found that some part of self was not usually presented in the physical world and believe that revealing that side through a selfie is an honest action to stay true to friends.

\section{Discussion}

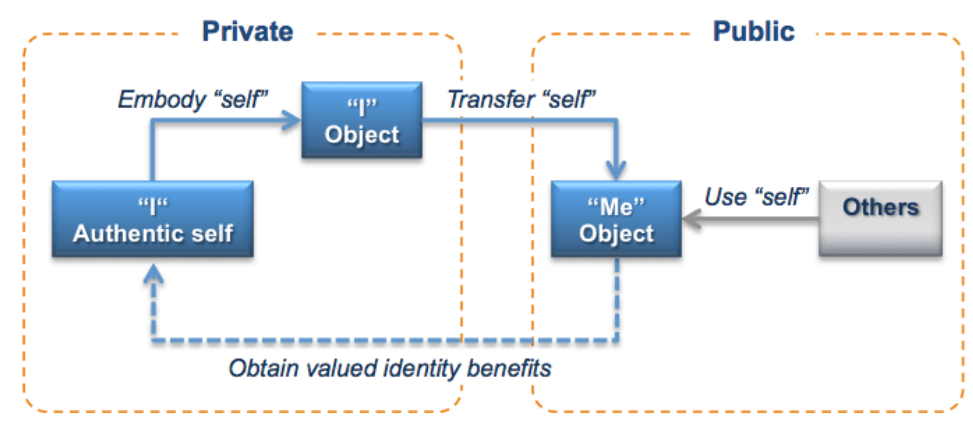

Figure 1. Objectification and consumption of self

Findings are summarized in Figure 1, which depicts the process by which selfies are taken, transferred (i.e., posted), and used. Pictures are produced to represent a person's self-image and then presented on social networking sites where other people can respond. After the owners interact with other people about the posting for a day or two, this cycle continues. The model in Figure1 shows the process as if the next cycle begins after a person gains identity benefits from the use process. In fact, consumers do not necessarily wait for the antecedent step to be completed before taking more selfies. The model is a conceptual representation of the consumption of a selfie. Consumers take selfies whenever they wish, then they transfer their self-images to social media in the hope of maintaining or increasing the number of interactions.

Throughout selfie practice, consumers acquire benefits that are favorable to their identity projects. These benefits correspond with the valued identity benefits that consumers gain in the quest for authenticity in Beverland and Farrelly's (2010) study-feeling connected, feeling in control, and feeling virtuous. Consumers find cues of the 
feelings of connection, control, and virtue from the interactions that occur on social media and these benefits are promotive of consumer identity projects. The ongoing interactions and the identity benefits gained create a feeling of genuine experience and connection to the real world. As a result, consumers feel true to themselves leading to a notion of self-authenticity. We conclude that consumers embark on a quest for the perception of authentic self through the selfie practice and the experiences reflect consumers' quest for existential authenticity in consumption.

We view the selfie practice as a type of consumption through objectification of self. Objectification theory explains that self-objectification results in psychological disorder (Fredrickson \& Roberts, 1997). However, we find the negative nature of objectification theory does not apply to the objectification of self in selfie. In the selfie, the self is carefully and strategically objectified. Therefore, the objectified self is not as vulnerable as a woman, as Fredrickson and Roberts (1997) explain. Even if a consumer internalized the same kind of appearance-oriented socio-cultural standards, this new form of objectified self in the digital age provides a self-image that is durable enough to sustain her. In addition, the consumer receives feedback through social interactions on social media, which gives self-confirmation and which makes the consumer willingly consume the self again. The social confirmation serves as a critical device that prevents a consumer's self-concept from deteriorating in opposition to the traditional perspective of objectification theory.

We also believe the complicated self-perception involved in selfie as a distinct feature of selfie. Even though it takes a form of self-objectification, the selfie reflects the $I$ state (i.e., the knower) as well as the $M e$ state (i.e., the known) of self. Traditional photographic portraits never generate the same meanings to consumers. A selfie combines the active aspect of person and the objective awareness of self. The active aspect of self-perception does not let a person fall into the fully objectified state. A selfie is the existential evidence of self in the form of objectified self.

Selfie consumption shows the relational aspect of consumption. The major channel through which consumers gain identity benefits in social media is the selfie. The main interest of the consumption object (i.e., selfie) is the self and the use process is almost co-consumption: to consume one's selfie with other people. It is unique in that a consumer attempts to but cannot control the use of the selfie. Although a selfie is an outcome of careful planning, no one can fully control the comments and the reactions to them. This uncertainty is both a risky and an alluring aspect of selfie practice.

The selfie reflects the cultural contradiction embedded in contemporary consumer culture: authenticity and self-promotion (Pooley, 2010). Consumers are motivated to find and express their true self but they also carefully manage their impressions and cultivate that self (Pooley, 2010). The production and use of selfies confirm this fundamental contradiction. The beauty of the selfie is to promote oneself, but consumers portray themselves not only as an attractive but also as sincere. Drawing upon Pooley (2010), the selfie ensures consumers' individuality by revealing and cultivating the image of their authentic self. Pooley (2010) attributes this cultural contradiction of consumerism to two moral ideals that Taylor (1989) identifies in the history of the modern West: self-responsible freedom and expressivism. The ideal of self-responsible freedom, dating to the nineteenth-century ethic of self-mastery, leads to disengagement of and control to one's self. Expressivism, dating to the twentieth-century call for self-fulfillment, is a quest for uniqueness, which answers the questions raised in a society of anonymity and materialism. Pooley (2010) maintains that consumerism presents authenticity as "a means to the end of promotion" (p. 78). "The best way to work on yourself is to consciously cultivate an authentic persona" (Pooley, 2010, p. 78). This study confirms this contradiction of the twenty-first century consumers' pursuit of a true but better self.

In most commodity consumption, a stock decreases as one continues to use it. Without spending a great deal of money, young adult consumers can produce and use as many selfies as they wish. This consumer-driven culture has created new terms or has influenced marketers. For example, there is a new Korean slang expression: Ul-jang angle. Ul-jang is a compound word of face and the best. It refers to a camera angle that is slightly higher than one's face. People find that the Ul-jang provides the most flattering photos of one's face. It is now the most popular up-close portrait photograph. As selfie became one of the important usages of digital camera or cellphone camera, marketers began taking practical implications from selfie practice. The needs of selfie takers feed into new product development such as a selfie stick that allows the ul-jang angle, a mirrorless DSLR camera with a 180-degree tilting LCD window, a motion-detecting shutter, and a camera with wireless internet for transferring images. We suggest that marketers take more implications from deep meanings of selfie photography. Understanding consumer meanings that are beyond taking flattering images will be conducive to creating values that camera or photographic equipment and selfie experiences involve. 
The limitation of this study lies in the demographic distribution of the sample. Interviews were collected only in Seoul and its suburbs. All of the interviewees were college students but the people who are most likely to take selfies range from tweens to adults. Although we selected college students in order to examine relational behaviors and their relationship to self-image, a future study with younger group whose self-concept is under-developed and a study of body image and selfies would be beneficial.

\section{References}

Ahuvia, A. C. (2005). Beyond the extended self: Loved objects and consumers' identity narratives. Journal of Consumer Research, 32(1), 171-184. http://dx.doi.org/10.1086/429607

Baudrillard, J. (1994). Simulacra and simulation (S. F. Glaser, Trans.). The University of Michigan Press.

Belk, R. W. (1988). Possessions and the extended self. Journal of Consumer Research, 15(2), 139-168. http://dx.doi.org/10.1086/209154

Belk, R. W. (2014). Objectification and anthropomorphism of the self. In S. Brown, \& S. Ponsonby-McCabe (Eds.), Brand mascots and other marketing animals (pp. 19-34). New York: Routledge.

Berger, P. L., \& Luckmann, T. (2011). The social construction of reality: A treatise in the sociology of knowledge. New York: Open Road Media.

Beverland, M. B., \& Farrelly, F. J. (2010). The quest for authenticity in consumption: Consumers purposive choice of authentic cues to shape experienced outcomes. Journal of Consumer Research, 36(5), 838-856. http://dx.doi.org/10.1086/615047

Beverland, M. B., Farrelly, F., \& Quester, P. G. (2010). Authentic subcultural membership: Antecedents and consequences of authenticating acts and authoritative performances. Psychology and Marketing, 27(7), 698-716. http://dx.doi.org/10.1002/mar.20352

Gao, L., Wheeler, S. C., \& Shiv, B. (2009). The "shaken self": Product choices as a means of restoring self-view confidence. Journal of Consumer Research, 36(1), 29-38. http://dx.doi.org/10.1086/596028

Gecas, V. (1991). The self-concept as a basis for a theory of motivation. In J. Howard, \& P. Callero (Eds.), The self-society dynamic (pp. 171-187). New York: Cambridge University Press. http://dx.doi.org/10.1017/ CBO9780511527722.010

Gerick, B. (2014, March 2). Oscars 2014: Ellen Degeneres' all-star selfie sets twitter record for most retweets. Retrieved from http://www.nydailynews.com/entertainment/oscars/degeneres-all-star-oscar-selfie-setstwitter-record-article-1.1708566

Glaser, B. G., \& Strauss, A. L. (1967). The discovery of grounded theory: Strategies for qualitative research. Chicago: Adline Publishing Company.

Grayson, K., \& Martinec, R. (2004). Consumer perceptions of iconicity and indexicality and their influence on assessments of authentic market offerings. Journal of Consumer Research, 31(2), 296-312. http://dx.doi.org /10.1086/422109

Havens, L. (1986). A theoretical basis for the concepts of self and authentic self. Journal of the American Psychoanalytic Association, 34(2), 363-378. http://dx.doi.org/10.1177/000306518603400206

James, W. (1890). The principles of psychology. New York: Hold and Company. http://dx.doi.org/10.1037/ 11059-000

Leigh, T. W., Peters, C., \& Shelton, J. (2006). The consumer quest for authenticity: The multiplicity of meanings within the mg subculture of consumption. Journal of the Academy of Marketing Science, 34(4), 481-493. http://dx.doi.org/10.1177/0092070306288403

Mead, G. H. (1934). Mind, self, and society: From the standpoint of a social behaviorist. Chicago: University of Chicago Press.

Merriam-Webster. (2014). Selfie. Retrieved from http://www.merriam-webster.com/dictionary/selfie

Nuttall, P. (2009). Insiders, regulars and tourists: Exploring selves and music consumption in adolescence. Journal of Consumer Behaviour, 8(4), 211-224. http://dx.doi.org/10.1002/cb.286

Pine, J. B., \& Gilmore, J. H. (1999). The experience economy. Boston: Harvard Business School Press. 
Pooley, J. (2010). The consuming self from flappers to facebook. In M. Aronczyk, D. Powers, \& P. Lang (Eds.), Blowing up the brand: Critical perspectives on promotional culture (pp. 71-90). New York: International Academic Publishers.

Sartre, J. P. (1943). Being and nothingness: A phenomenological essay on ontology. New York: Philosophical Library.

Schlenker, B. R. (1980). Impression management. Monterey, CA: Brooks/Cole Publishing Company.

Soltis, A. (2013, December 10). Michelle not amused by Obama's memorial selfie. Retrieved from http://nypost.com/2013/12/10/michelle-annoyed-by-obamas-selfie-at-mandela-memorial/

Talyor, C. (1989). Sources of the self: The making of the modern identity. Cambridge, MA: Harvard University Press.

Vannini, P., \& Williams, J. P. (2009). Authenticity in culture, self, and society. In P. Vannini, \& J. P. Williams (Eds.), Authenticity in culture, self, and society (pp. 1-20). Cornwall, Great Britain: Ashgate.

Wang, N. (1999). Rethinking authenticity in tourism experience. Annals of Tourism Research, 26(2), 349-370. http://dx.doi.org/10.1016/S0160-7383(98)00103-0

Weigert, A. J. (2009). Self authenticity as master motive. In P. Vannini, \& J. P. Williams (Eds.), Authenticity in culture, self, and society (pp. 37-50). Cornwall, Great Britain: Ashgate.

Wikipedia. (2014, September 3). Selfie. Retrieved from http://en.wikipedia.org/wiki/Selfie

Yeung, K. T., \& Martin, J. L. (2003). The looking glass self: An empirical test and elaboration. Social Forces, 81(3), 843-879. http://dx.doi.org/10.1353/sof.2003.0048

\section{Copyrights}

Copyright for this article is retained by the author(s), with first publication rights granted to the journal.

This is an open-access article distributed under the terms and conditions of the Creative Commons Attribution license (http://creativecommons.org/licenses/by/3.0/). 